\title{
Modeling of concrete carbonation in deep geological disposal of intermediate level waste
}

\author{
P. Thouvenot ${ }^{1}$, O. Bildstein ${ }^{1}$, I. Munier ${ }^{2}$, B. Cochepin ${ }^{2}$, S. Poyet ${ }^{3}$, X. Bourbon $^{2}$ and E. Treille ${ }^{2}$ \\ ${ }^{1}$ CEA, DEN, DTN, SMTM, LMTE, F-13108 Saint-Paul-lez-Durance, France \\ ${ }^{2}$ Andra, Research and Development Division, Châtenay-Malabry, France \\ ${ }^{3}$ CEA, DEN, DPC, SECR, LECBA, F-91191 Gif-sur-Yvette, France
}

\begin{abstract}
Simulations of atmospheric carbonation of Intermediate-Level Long-lived radioactive Waste (ILLW) concrete packages were conducted to evaluate their possible chemical degradations. Two-phase liquid water-air flow is combined with gas component diffusion processes leading to a progressive drying of the concrete. Complete drying of the $11 \mathrm{~cm}$ thick waste disposal package wall occurs over a period ranging from 2 years for the low-performance concrete to 10 years for the highperformance concrete. The drying process slows down when transport characteristics of concretes are enhanced. Carbonation depths in the order of 2 to $3 \mathrm{~cm}$ in 100 years are predicted for this cementitious component. However, these values are slightly overestimated compared to experimental data. Also the kinetic model of mineral reactivity requires improvements with respect to the protective effect of secondary carbonates and to thermodynamic data.
\end{abstract}

\section{Introduction}

The French management of High-level Long-lived Waste (HLW) and Intermediate-Level Long-lived radioactive Waste (ILLW) is entrusted to Andra (the French National Radioactive Waste Management Agency) and is based on waste disposal in deep geological formation of CallovoOxfordian claystone located in the eastern part of the Paris Basin [1]. During the operating period of the ILLW disposal zone (up to 100 years), concrete components (waste disposal packages, concrete vaults...) will be ventilated in order to guarantee operating safety and to contribute to the evacuation of residual heat from the waste. The ventilation air, drawn from the surface, will desaturate the concrete components, leading to atmospheric carbonation and potentially progressive lowering of $\mathrm{pH}$ inside the cement paste. This process could favour corrosion of the steel reinforcements, which may have deleterious effects on the waste disposal package integrity.

Simulations of carbonation processes were obtained using a 1D geometry with the ToughReact ( $v$ 1.2) reactive-transport numerical tool [8]. The modelling of concrete degradation takes into account different processes such as the feedback between the diffusion coefficient and the saturation/porosity evolution, which are linked through volumetric balance of mineral dissolution and precipitation reactions using a generalized Millington-Quirk relationship. 


\section{Conceptualisation of concrete components}

ILLW vaults components constitute a complex 3D geometrical system (Fig. 1). The ILLW disposal structure is about $10 \mathrm{~m}$ in diameter and up to $250 \mathrm{~m}$ length with a $50 \mathrm{~m}$ long access drift (Fig. $1 \mathrm{~A}$ ). This cementitious structure containing the waste disposal packages (Fig. 1.B) is in contact with the clay host rock. The 1.4-meter high and 0.11-meter thick reinforced walls concrete container houses four primary waste drums [1].
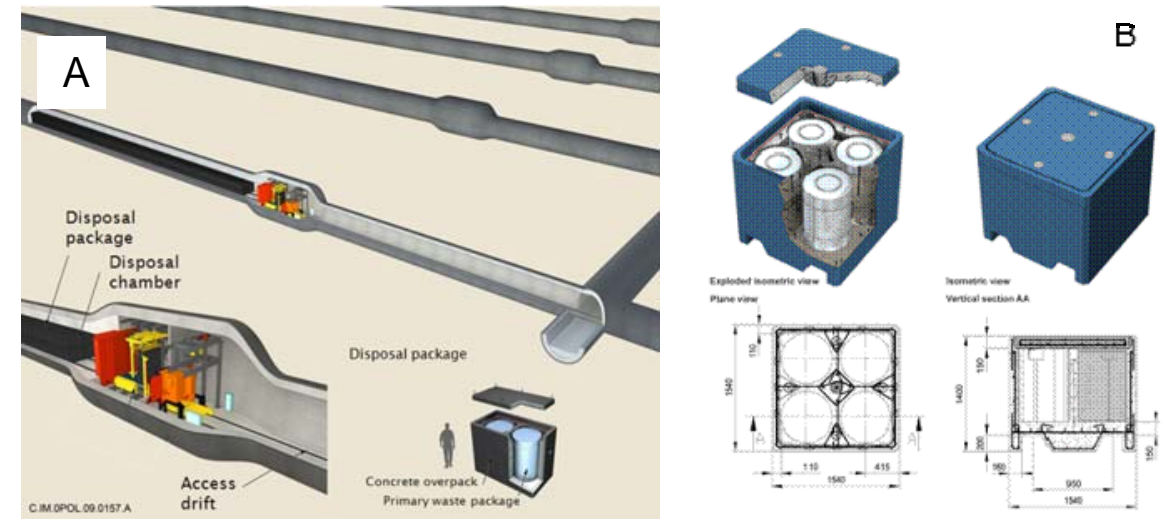

Fig. 1. Concrete components - A: view of the ILLW disposal cell - B: view of the ILLW disposal package.

\section{Simulated processes and material properties}

\subsection{Processes}

Atmospheric carbonation of concrete in unsaturated conditions is a complex process that involves intricate couplings between transport of water and $\mathrm{CO}_{2}$ in both gas and liquid phases, capillary flow during drying of the concrete, and chemical reactions involving cement hydrates and $\mathrm{CO}_{2}$ dissolved in the aqueous phase.

$\mathrm{CO}_{2}$ diffuses from the single-phase gas boundary condition into the partially saturated pore space of concrete and dissolves in the pore water. Hydrates in the cement (mainly portlandite and CSH phases) are then subject to carbonation reactions, producing calcite and other secondary minerals having a smaller $\mathrm{Ca} / \mathrm{Si}$ ratio. A $\mathrm{pH}$ front progressively develops and migrates inside the concrete, from $\mathrm{pH} \sim 8.5$ in regions where carbonation is complete to $\mathrm{pH} \sim 13.3$ in the non-disturbed concrete.

In these calculations, Darcy flow of liquid water and air is considered, taking into account capillary forces and the Klinkenberg effect in the gas phase. Vapour pressure lowering, due to capillarity effects, is also accounted for, as described by Kelvin's model [2,3]. Wetting properties and relative permeability of the media are expressed using the van Genuchten - Mualem [4] (liquid phase) and Parker (gaseous phase) models [3].

Both aqueous and gaseous diffusion are taken into account but focus is given here on gaseous diffusion which plays a major role in the drying and carbonation processes. Dripping is not considered in the present model and transport of water out of the concrete is initiated by water vapour diffusion to the external boundary of the component (where the dry ventilation air is represented by a boundary condition). Thus, the nonlinear expression of tortuosity in the water vapour diffusion process [2,5] plays a key role in the initiation of atmospheric carbonation. For lowpermeability concrete materials, expressions adopted for the diffusion coefficient are similar to the classical Millington and Quirk [6] model developed for soils: 


$$
D_{i}^{j}=\omega \tau_{0} \tau_{i} d_{i}^{j}=\omega\left(\omega^{a} S_{i}^{b}\right) d_{0, i}^{j}
$$

where $D_{i,}^{j}$ is the effective diffusion coefficient of component $j$ in phase $i, d_{0, i}{ }^{j}$ is the molecular diffusion coefficient of component $i$ in phase $j, \omega$ is the porosity, $\tau_{0}$ is the tortuosity of the porous media, and $\tau_{\mathrm{i}}$ is the tortuosity due to phase arrangement in the porosity. In the second part of eq. 1 , the tortuosities are expressed as a function of the porosity and $S_{i}$, the saturation with respect to phase $i$, and empirical exponents $a$ (the cementation factor) and $b$ (see Table 1). Exponent $b$ plays an important role in the dynamics of drying, because it creates a strong positive feedback between water vapour diffusion and gas-saturation.

Dissolution and precipitation of minerals are considered with symmetric kinetic rate laws. In a first approach, the kinetic model does not include the effect of liquid saturation on reaction rates.

\subsection{Composition and physical properties of components}

The simulations are performed with three different concretes: 1 ) a high-performance concrete (HPC) having hydraulic properties corresponding to those of a fresh sample prepared in laboratory at a small scale, 2) a low-performance concrete (LPC) whose hydraulic properties take into account the scale effect for industrial and/or altered objects and 3) an intermediate-performance concrete (IPC). Table 1 summarizes the main hydraulic and transport properties of the three considered cementitious materials. In the simulations, a factor of 100 between gas and liquid intrinsic permeabilities was assumed.

Table 1. Concrete hydraulic and transport properties.

\begin{tabular}{|l|c|c|c|}
\hline & $\begin{array}{c}\text { High } \\
\text { Performance } \\
\text { Concrete (HPC) }\end{array}$ & $\begin{array}{c}\text { Intermediate } \\
\text { Performance } \\
\text { Concrete (IPC) }\end{array}$ & $\begin{array}{c}\text { Low } \\
\text { Performance } \\
\text { Concrete (LPC) }\end{array}$ \\
\hline Porosity & 0.08 & 0.12 & 0.16 \\
\hline Permeability water ( $\left.{ }^{2}\right)$ & $1.010^{-21}$ & $1.010^{-19}$ & $1.010^{-17}$ \\
\hline Permeability to gas (m $\left.{ }^{2}\right)$ & $1.010^{-19}$ & $1.010^{-17}$ & $1.010^{-15}$ \\
\hline Molecular diffusion coefficient in water $\left(\mathrm{m}^{2} / \mathrm{s}\right)$ & $1.910^{-9}$ & $1.910^{-9}$ & $1.910^{-9}$ \\
\hline Molecular diffusion coefficient for vapour $\left(\mathrm{m}^{2} / \mathrm{s}\right)$ & $2.410^{-5}$ & $2.410^{-5}$ & $2.410^{-5}$ \\
\hline Molecular diffusion coefficient for $\mathrm{CO}_{2}(\mathrm{~g})\left(\mathrm{m}^{2} / \mathrm{s}\right)$ & $1.610^{-5}$ & $1.610^{-5}$ & $1.610^{-5}$ \\
\hline Millington-Quirck parameter a & 2.0 & 2.0 & 2.0 \\
\hline Millington-Quirck parameter b & 4.2 & 4.2 & 4.2 \\
\hline van Genuchten Pr (Pa) & $45.010^{6}$ & $15.010^{6}$ & $5.010^{6}$ \\
\hline van Genuchten n & 1.93 & 1.74 & 1.58 \\
\hline Klinkenberg factor (Pa) & $4.510^{5}$ & $4.510^{5}$ & $4.510^{5}$ \\
\hline
\end{tabular}

Concrete is a mixture of aggregates (mainly calcite) and cement paste. Mineral composition considered in the model for the concrete [1,7] is given in Table 2 . 
Chemical reactions occurring at the air/concrete boundary result in the dissolution of the primary minerals and the precipitation of secondary minerals. The set of secondary phases considered in the simulations includes: oxides (magnetite), hydroxides (brucite, gibbsite, $\mathrm{Fe}(\mathrm{OH})_{3}$ ), silicates (amorphous silica, sepiolite, CSH 1.2, CSH 0.8, straetlingite, katoite_Si), carbonates (calcite, nahcolite), and other minerals (hydrotalcite- $\mathrm{CO}_{3}$, ettringite, dawsonite, gypsum, burkeite, syngenite, glaserite, arcanite, glauberite, polyhalite). A secondary calcite was distinguished from aggregate calcite, the latter being considered as an inert phase due to low reactivity of aggregates.

Table 2. Mineralogical composition of concrete.

\begin{tabular}{|c|c|c|}
\hline Mineral & Composition & Volume \% \\
\hline Calcite & $\mathrm{CaCO} 3$ & 72.12 \\
\hline Portlandite & $\mathrm{Ca}(\mathrm{OH}) 2$ & 5.73 \\
\hline CSH 1.6 & $\mathrm{Ca} 1.6 \mathrm{SiO} .26: 2.58 \mathrm{H} 2 \mathrm{O}$ & 13.76 \\
\hline Monocarboaluminate & 3CaOAl2O3CaCO3:10.68H2O & 2.26 \\
\hline Ettringite & $\mathrm{Ca} 6 \mathrm{Al} 2(\mathrm{SO} 4) 3(\mathrm{OH}) 12: 26 \mathrm{H} 2 \mathrm{O}$ & 3.60 \\
\hline Hydrotalcite & $\mathrm{Mg} 4 \mathrm{Al} 2(\mathrm{OH}) 14: 3 \mathrm{H} 2 \mathrm{O}$ & 0.39 \\
\hline & $\mathrm{Ca} 3 \mathrm{Fe} 2(\mathrm{OH}) 12$ & 2.05 \\
\hline
\end{tabular}

All solid-solution reactions are described with a kinetic model, based on a review of data published in the literature. However, large uncertainties remain on the reaction rate constants for many phases, as well as on the actual reactive surfaces. Reaction rates were modified as a function of temperature using an Arrhenius type law.

\section{Simulation tools and configurations}

The equations of state EOS4 and EOS9 modules of the Toughreact code [8] were used in this study to describe the drying of concrete. The choice of EOS4 makes it possible to calculate the two-phase flow together with reactive transport in such materials where pressure-lowering effects are significant. The EOS9 module of ToughReact is based on the Richards' equation which describes unsaturated flow systems where the advective flow of the gas phase is not taken into account.

Several adaptations of the EOS4 module available in ToughReact version 1.2 were developed to describe the drying concrete process: (1) an extended model for porosity/saturation-dependent tortuosity (a generalized form of the Millington-Quirk tortuosity law), as shown in Eq. (1), and (2) an additional "slipping" factor was introduced to allow for the difference between intrinsic material permeability with respect to the gas phase and to the liquid phase (Table 1), consistent with material data from the literature $[1,2]$.

The carbonation simulations were performed using the Thermoddem lv12 (2008) database, developed by BRGM (Orléans, France) [9].

For the waste disposal package (Fig. 1.B) simulations, only a $1 \mathrm{D}$ half section of the concrete container (section $=0.11 \mathrm{~m}$ ) is represented, assuming that atmospheric carbonation occurs on both faces of the wall. Initial liquid water saturation of the material is assumed to be 0.8 . The ventilation air temperature is $25^{\circ} \mathrm{C}$ and the relative humidity is $40 \%$. 


\section{Simulation results}

\subsection{Concrete drying process}

Using the multiphase module EOS4 with the assumption of an initial saturation of 0.8 , complete drying (i.e. equilibrium with the ventilation air at a relative humidity of 40\%) of the $11 \mathrm{~cm}$ thick waste disposal package wall proceeds in about 2 years for the LPC versus about 5 years for the IPC and about 10 years for the HPC (Fig. 2, grey curves). The drying process slows down when transport properties of concrete are improved. The complete drying simulated with the Richards' equation (EOS9 module, see black curves in Fig. 2) is slightly slower than with the EOS4 for each type of concrete.
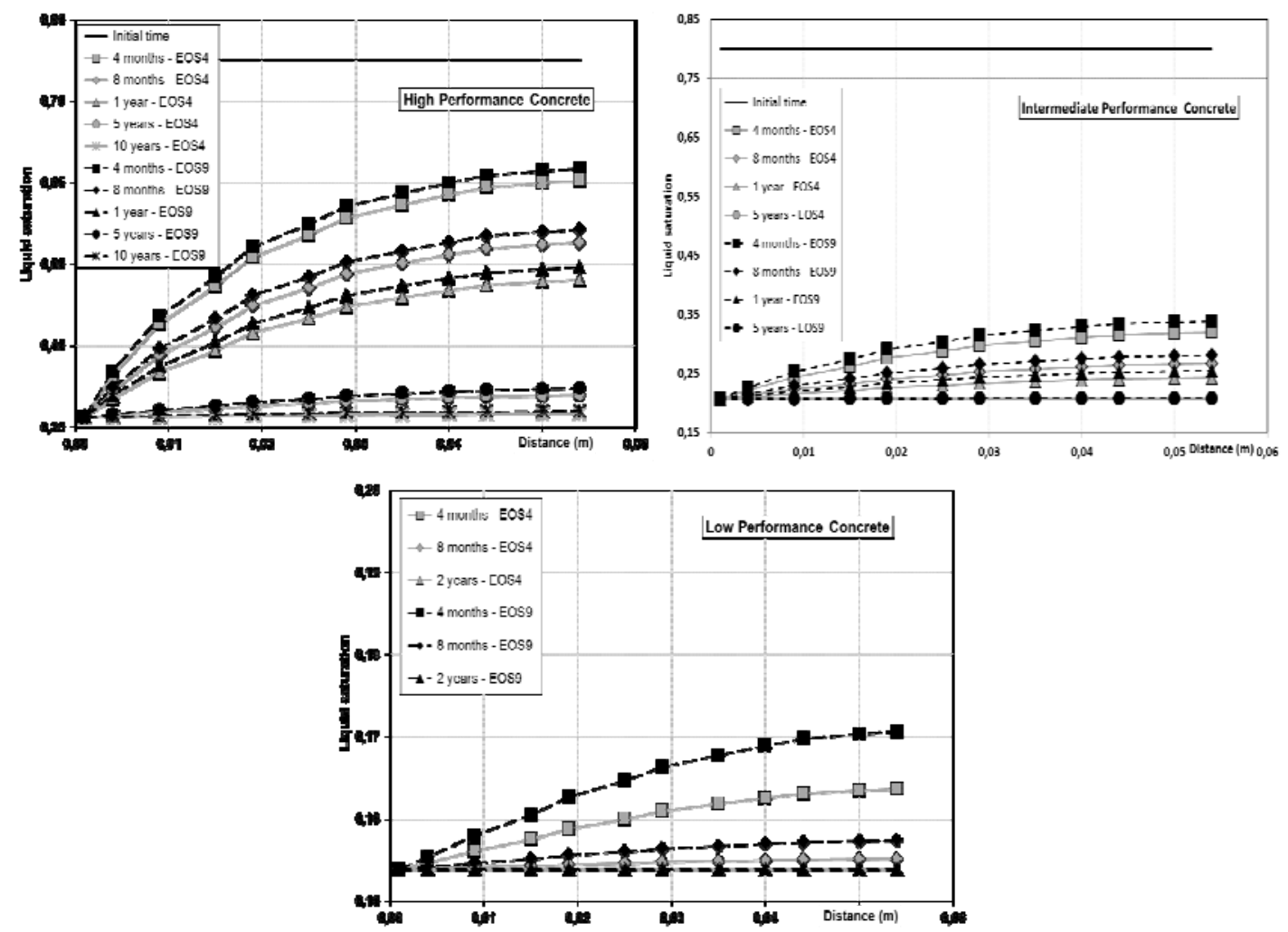

Fig. 2. Evolution of the liquid saturation profiles with time for the three concrete materials.

Simulations performed with the full multiphase EOS4 module lead to a slightly faster drying process due to a small contribution from water vapour diffusion. However, the differences between both models for the three concrete materials are not very large. Note that water consumed during carbonation is not accounted for in the computed water mass balance, i.e., there is no feedback between chemical reactions and flow calculations in the code.

\subsection{Concrete carbonation process}

Carbonation simulations are performed with the multiphase EOS4 module. All the simulation results shown below correspond to the IPC material. With this material, the $\mathrm{pH}$ has decreased from 13.3 to 8, over a thickness of about $2 \mathrm{~cm}$ in 100 years, due to the carbonation reaction (Fig. 3). Note that, after 100 years, the carbonation depth is only $1 \mathrm{~cm}$ for the HPC and up to $4 \mathrm{~cm}$ for the LPC. 


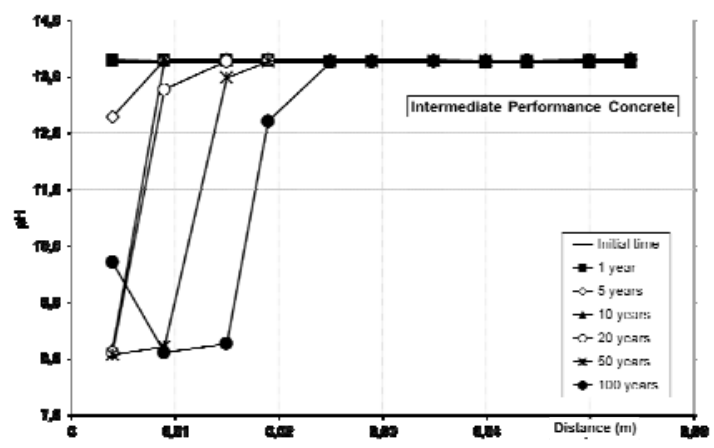

Fig. 3. Evolution of pH profiles for the Intermediate Performance Concrete (calculated with the EOS4 module).

The location of the portlandite dissolution and the calcite precipitation fronts (Fig. 4) coincides with the $\mathrm{pH}$ front ( $2 \mathrm{~cm}$ carbonation depth after 100 years). The evolution of the profiles for $\mathrm{CSH}$ phases as a function of time (Fig. 5.a) shows the dissolution of CSH 1.6 which is progressively replaced by $\mathrm{CSH}$ 0.8, CSH 1.2 and straetlingite, and ultimately transformed into amorphous silica. The degradation depth of CSH 1.6 also corresponds to the propagation front of low pH values $(2 \mathrm{~cm}$ in 100 years). Similarly, the primary sulphate-rich mineral (ettringite) is completely dissolved in favour of gypsum (Fig. 5.b). Precipitation of small quantities of other secondary phases (sepiolite, gibbsite, katoite-Si) in the alteration zone of the concrete is also predicted.
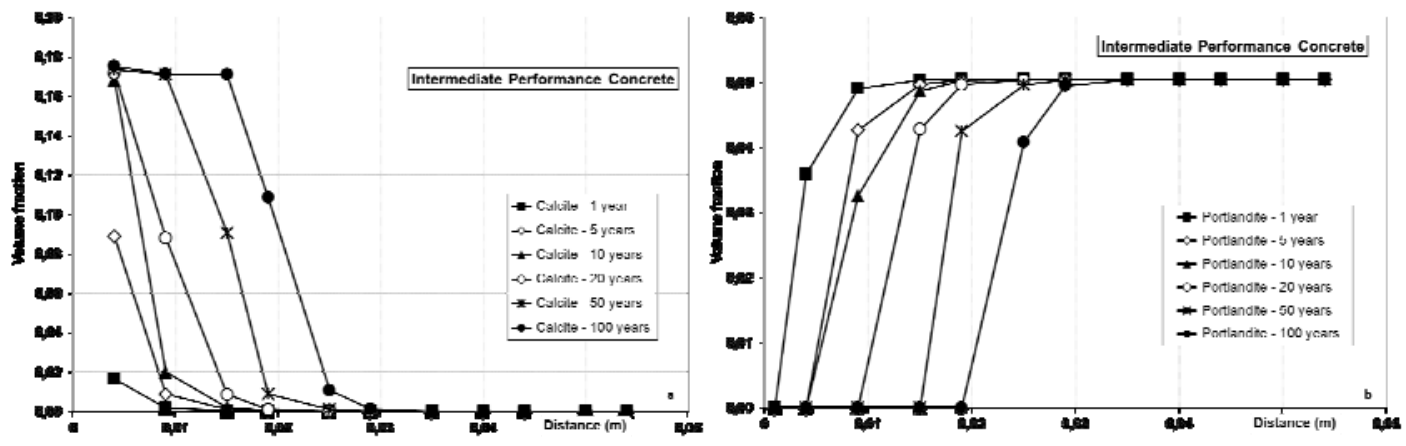

Fig. 4. Evolution of volume fraction profiles for calcite (a) and portlandite (b) for the Intermediate Performance Concrete (calculated with the EOS4 module).
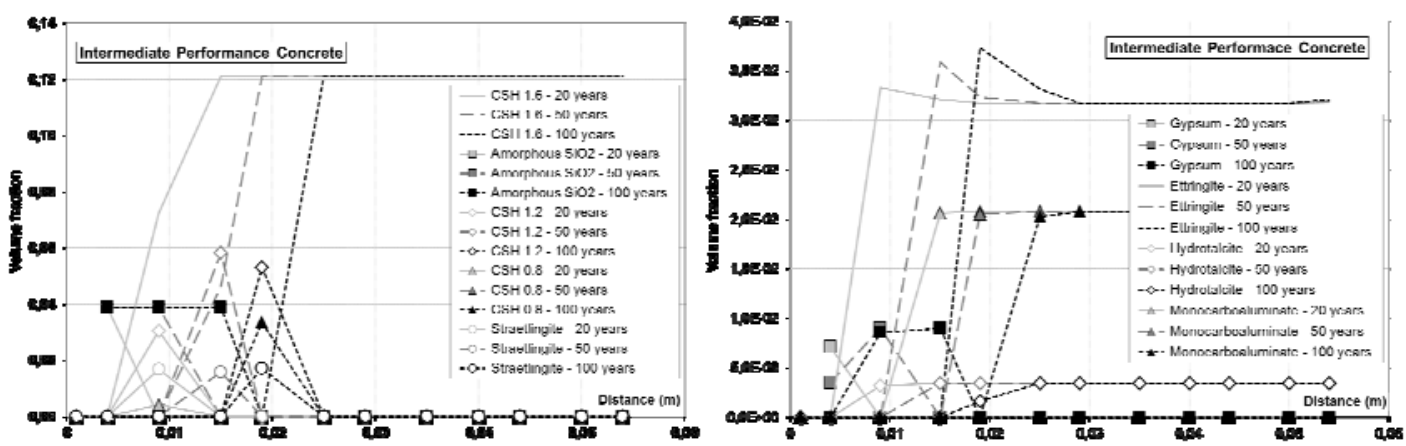

Fig. 5. Evolution of volume fraction profiles for CSH phases and amorphous silica (a) and selected accessory phases (b) for the Intermediate Performance Concrete (calculated with the EOS4 module) 
The progress and extent of the $\mathrm{pH}$ front and the transformation of portlandite and other cement hydrates into calcite are strongly correlated with the transport and hydraulic properties of the cementitious materials (simulations results not shown here).

Comparison with experiments reveals that the concrete drying front propagation and the carbonation intensity predicted in the simulations are overestimated. These results were obtained without considering the effect of the liquid saturation on mineral reactivity. However, laboratory tests have shown that carbonation reactions are strongly inhibited in a dry material, as soon as liquid saturation is lower than $\sim 0,3$ [10]. This phenomenon has to be taken into account to correctly adjust the dynamics of drying [2], which is strongly coupled to carbonation. A new functionality was therefore introduced to describe the dependency of the kinetics of the chemical process with respect to water saturation. An arbitrary linear function was initially tested to describe a reactivity decrease when liquid saturation drops below 0.3 and full reactivity when liquid saturation is higher than 0.7 (Fig. 6). In this case the process of carbonation is almost completely stopped since a drying state lower than a liquid saturation of 0.3 is reached in less than 6 months. A more phenomenological approach was adopted using a Bazant type function [11], in which the reactivity progressively decreases when liquid saturation vanishes according to a power function: $R=1 /\left[1+625 /\left(1-S_{l}\right)^{4}\right]$ (Fig. 6).

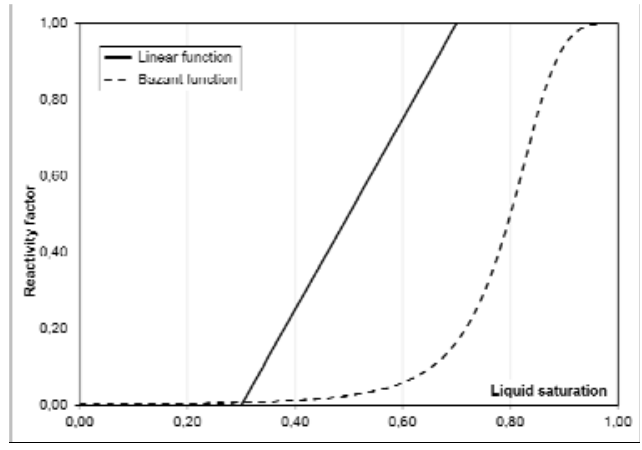

Fig. 6. Chemical reactivity factor as a function of the liquid saturation.

The profiles of mineral phases shown in Fig. 7 were obtained using the Bazant function. A significant reduction in the amplitude of carbonation is then observed: lower dissolution of the primary minerals such as portlandite (fig. 8.a) or CSH 1.6 (fig. 8.b) and lower precipitation of the secondary minerals such as straetlingite, amorphous silica, CSH 0.8, and CSH 1.2. This lower reactivity is accompanied by a deeper propagation of the degradation front due to the lower consumption of $\mathrm{CO}_{2}$ at the surface, which then migrates and reacts over longer distances into the concrete ( $3 \mathrm{~cm}$ after 100 years, instead of $2 \mathrm{~cm}$ in the reference case).
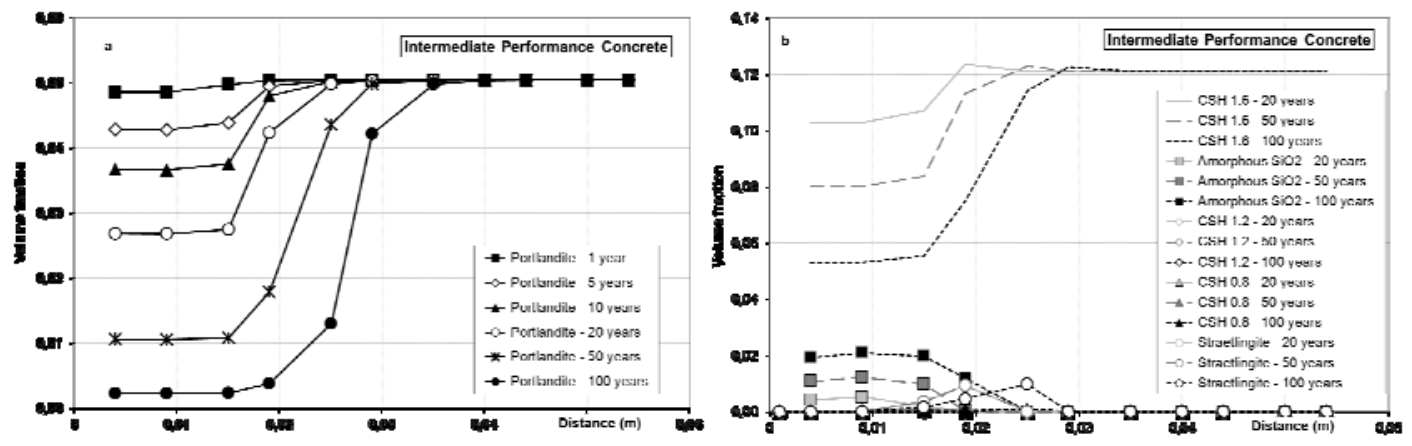

Fig. 7. Evolution of volume fraction for portlandite (a) and CSH phases and amorphous silica (b) for the Intermediate Performance Concrete (calculated with the EOS4 module using liquid saturation effect). 


\section{Conclusion and discussion}

Integrated 1D simulations of atmospheric carbonation coupled with the drying process of ILLW concrete disposal packages in deep geological conditions during the operating period were performed. Complete drying of the $11 \mathrm{~cm}$ thick waste disposal package wall occurs over a period ranging from 2 years for the low-performance concrete to 10 years for the high-performance concrete. The drying process slows down when hydraulic and transport properties of the cementitious material are enhanced. The simulations also provide a first evaluation of total carbonated depth: about $2 \mathrm{~cm}$ after 100 years. These first simulations do not take into account the decrease of chemical reactivity with the decrease of the material water content. The second set of simulations, which takes into account this phenomenon via a Bazant type function, leads to a less intense but deeper carbonation of the cementitious material (about $3 \mathrm{~cm}$ after 100 years).

In the simulated reaction path of concrete carbonation, the early precipitation of amorphous silica as a prominent and ultimate alteration phase for calcium silicate hydrates is quite crude and does not fit well with experimental observations, although amorphous silica has indeed been identified among these phases [12,13]. Improvement in this field will probably come from a better knowledge of the kinetics of $\mathrm{CSH}$ alteration for low $\mathrm{Ca} / \mathrm{Si}$ ratios.

The range of carbonation intensity is also considered to be overestimated since experimental work has shown the presence of significant portlandite residual amounts in carbonated concrete [9]. As a consequence, carbonation intensity is reduced and a substantial proportion of hydrates remain unaltered in the carbonated profile thus preserving the mechanical properties of the concrete. This observation, which is partially reproduced by introducing the effect of liquid saturation, may also be due to the protective effect of secondary carbonate mineral precipitation. The latter process has also been developed in the numerical model but not used in this paper. Specific experimental results will be required in order to discriminate the liquid saturation effect from the "armouring" effect.

Further progress can be achieved, e.g. by coupling more tightly gas transport and chemical reactions and by parallelizing parts of the numerical algorithm in order to gain at least one order of magnitude in CPU time.

\section{Acknowledgment}

N. Spycher (Lawrence Berkeley National Laboratory) are gratefully acknowledged for their help in building and improving the TOUGH scripts and for their insightful remarks on multiphase physics.

B. Bary (CEA/DEN LECBA) is acknowledged for his help on concrete physics.

\section{References}

1. Andra, Dossier Argile, Châtenay-Malabry, France (2005).

2. M. Thiery, V. Baroghel-Bouny, N. Bourneton, G. Villain and C. Stefani, Eur. J. Environ. Civil Engineering 11/5, 541 (2007).

3. K. Pruess, C. Oldenburg and G. Moridis, Report LBNL-43134, California, (1999).

4. M. Van Genuchten, Soil Sci. Soc. Am. J., 44, 892 (1980).

5. V. Baroghel-Bouny, M. Thiery, F. Barbaron, O. Coussy and G. Villain, Eur. J. Environ. Civil Engineering 11, 671 (2007).

6. R. J. Millington and J. P. Quirk, Trans. Faraday Soc. 57, 1200 (1961).

7. R. Belarbi, A. Aït-Mokhtar, M.Qin and O. Omicrine, Revue Européenne Génie Civil, 10/9, 1033 (2006).

8. T. Xu, E. Sonnenthal, N. Spycher and K. Pruess, Report LBNL-55460, Lawrence Berkeley National Laboratory, Berkeley, Calif. (2004).

9. Ph. Blanc, A. Lassin, P. Piantone et al. Appl. Geochem. 27, 10, 2107-2116 (2012).

10.M. Thiery, PhD Thesis, ENPC, Marne-la-Vallée, France (2005).

11. J. P. Bazant and L.J. Najjar, Mat. Construct. 5, 25 (1972).

12. F. P. Glasser, J. Marchand and E. Samson, Cem. Concrete Res. 38, 226 (2008).

13. L. Black, K. Garbev and I. Gee, Cem. Concrete Res. 38, 745 (2008). 